\title{
Properties of Cellulose Nanofibril Produced from Wet Ball Milling after Enzymatic Treatment vs. Mechanical Grinding of Bleached Softwood Kraft Fibers
}

\author{
Jinsong Zeng, ${ }^{\mathrm{a}}$ Lu Liu, ${ }^{\mathrm{a}}$ Jinpeng Li, ${ }^{\mathrm{a}}$ Jiran Dong, ${ }^{\mathrm{a}}$ and Zheng Cheng ${ }^{\mathrm{a}, \mathrm{b}, *}$ \\ Cellulose nanofibril (CNF) is a class of promising and renewable \\ nanocellulosic material due to its unique dimensional characteristics and \\ appealing properties. CNF preparations based on TEMPO pretreatment \\ followed by high-pressure homogenization have been studied intensively, \\ while the high energy consumption and the environmental issues remain \\ challenges to their application. Mechanical refining processes have been \\ commonly applied at the academic and industrial relevant scales for CNF \\ production. In this study, bleached softwood kraft pulp was subjected to \\ high-efficiency wet ball milling (following enzymatic pretreatment) and \\ mechanical grinding to obtain CNF. The effects of ball milling time, \\ grinding gap, and grinding passes on structure and properties of CNF were \\ evaluated. Scanning electron microscopy images confirmed that the \\ diameter of CNF was decreased with the increment of ball milling time and \\ number of grinding passes. The results indicated that ball milling time, \\ grinding gap, and grinding passes were important to increase the \\ dispersity of CNF suspensions. The degree of polymerization and \\ crystallinity index of CNF decreased with increasing ball milling time and \\ grinding passes.
}

Keywords: Cellulose nanofibril; Ball milling; Mechanical grinding

Contact information: a: State Key Laboratory of Pulp and Paper Engineering, Plant fiber research center, School of Light Industry and Engineering, South China University of Technology, No. 381, Wushan road, Tianhe district, Guangzhou, CN510640, China; b: School of Chemistry and Chemical Engineering, South China University of Technology, Guangzhou, CN 510640, China;

*Corresponding author: chengz@scut.edu.cn

\section{INTRODUCTION}

Cellulose nanofibril (CNF), a nano-scale material obtained from cellulose, has been used as a source for the development of bio-based functional materials with high volume. The CNF has many interesting and useful properties including high strength and stiffness, optical transparency, high thermal stability, low density, thermal insulation, and mechanical resistance (Osong et al. 2016; Marinhoa et al. 2020). The CNF has been already evaluated for a wide range of areas in science and technology, such as the production of paper-based products, nanocomposites, flexible electrodes, automotive components, biomedical devices, and foods, as well as in water treatment (Abdul Khalil et al. 2014; Mondal 2017; Francoa et al. 2019; Qi et al. 2019).

Different techniques, such as high-pressure homogenization, chemical treatment, and ultrafine grinding methods, have been employed to produce CNF (Bian et al. 2016; Nechyporchuk et al. 2016; Long et al. 2017). However, the main drawback of mechanical processing is the high energy consumption (Berglund et al. 2016). Spence et al. (2011), and it has been concluded that ultrafine grinding is the most efficient approach in terms of 
consumed energy for the CNF preparation. During the grinding, the cellulose slurry is passed between static and rotating grinding stones (disks). The distance between these disks can be precisely adjusted, which makes it possible to avoid the problem of clogging. By the shearing forces generated between the discs, the cell wall is delaminated and the CNF is individualized (Liu et al. 2018). Wang and Zhu (2016) reported on the effects of mechanical fibrillation time by disk grinding on the properties of resultant CNF films. They showed that it was possible to fractionate large networked CNF from small ones by centrifugation.

Ball milling is an environmentally friendly and low-cost method of producing CNF because of its ease of use, relatively inexpensive equipment, its combination of friction, collision, shear, and other mechanical actions to reduce the crystallinity of cellulose, and its applicability to essentially all classes of materials (Zhang et al. 2018; Ewulonu et al. 2019; Nagarajana et al. 2019). A planetary ball mill applies artificial gravitational force to the grinding medium by using a centrifugal force field. In a planetary mill, the grinding jar rotates around its own axis in a direction opposite to the direction of support plate rotation, which causes a non-uniform field of centripetal acceleration. Therefore, the balls in planetary mill have notably higher impact energies (Kim et al. 2013; Nobuta et al. 2016). Many researchers have used ball milling for the pretreatment of all classes of lignocellulosic materials prior to glucose production (Amiralian et al. 2015; Kwon et al. 2015, 2016; Du et al. 2017). Zhang et al. (2015) studied the process of CNF production from softwood pulp by ball milling. The effects of ball milling conditions including the ball-to-cellulose mass ratio, milling time, ball size, and alkaline pretreatment were investigated. Postproduction-treatments such as dimensional homogenization were also studied.

In this study, CNF was obtained from bleached softwood kraft pulp (BSKP), and the properties of $\mathrm{CNF}$ from wet ball milling and mechanical grinding were compared. Ball milling was combined with enzymatic pretreatment in order to decrease the energy consumption and to obtain high quality and homogeneity of the CNF. The process conditions, dispersity, morphology, degree of polymerization, and crystal structures of the resulting two kinds of CNF obtained were compared and discussed.

\section{EXPERIMENTAL}

\section{Materials}

Commercial dried BSKP was obtained from a paper mill (Guangdong, China). The pulp fibers were first soaked in deionized water overnight and then disintegrated in a lab Hollander beater for $10 \mathrm{~min}$. Commercial endoglucanase (Banzyme 2900) was purchased from UPM-kymmene Co. Ltd. (Jiangsu, China). The optimum $\mathrm{pH}$ and temperature for the Banzyme 2900 were 5.5 and $50{ }^{\circ} \mathrm{C}$, respectively. The cupriethylenediamine hydroxide solution was purchased from the China Pulp and Paper Research Institute (Beijing, China). Deionized water was used for all of the experiments.

\section{Enzymatic Pretreatment}

The BSKP fibers were pretreated with enzyme prior to ball milling under the following conditions: $50{ }^{\circ} \mathrm{C}, 7.0 \%$ pulp consistency, pH 5.5 (adjusted with citrate acidsodium citrate buffer), enzyme dosage of $9 \mathrm{mg} / \mathrm{g}$ based on the weight of dried pulp, $3.0 \mathrm{~h}$, at $200 \mathrm{rpm}$ for mechanical stirring in a reactor. After treatment, the enzyme was deactivated 
by increasing temperature to $100{ }^{\circ} \mathrm{C}$ for $15 \mathrm{~min}$. Subsequently, the slurry was centrifuged to separate the solid and liquid phases. The solid material was washed with deionized water several times. The washed solids were used for analysis and subsequent mechanical fibrillation.

\section{Ball Milling}

Cellulose materials were wet ball-milled with a PQ-N2 planetary ball mill (Livingston, NJ, USA). The enzymatically treated fibers were diluted to $1.0 \mathrm{wt} \%$ and then agitated by a mechanical blender for $10 \mathrm{~min}$. Then $150 \mathrm{~g}$ of the diluted fibril slurry were put into an agate jar of $500 \mathrm{~mL}$ capacity. One jar was loaded with a ball-to-cellulose mass ratio of $60: 1$. The weight ratio of the balls with $10 \mathrm{~mm}$ and $6 \mathrm{~mm}$ diameters was 5:3. The jar was rotated at a velocity of $30 \mathrm{~Hz}(387 \mathrm{rpm})$ with one rotation direction. The ball milling was carried out for $0.5,1.0,1.5,2.0$, and $3.0 \mathrm{~h}$ at room temperature in order to investigate the effect of ball milling time on the production of CNF. To prevent overheating of the cellulose, $10 \mathrm{~min}$ of interval was provided between every 5 min of milling. The preparation process is shown in Fig. 1b. The CNF produced from wet ball milling were marked as CNF-B.

\section{Mechanical Fibrillation by Ultrafine Grinder}

The raw BSKP fibers were immersed in deionized water for $2.0 \mathrm{~h}$ at $2 \%(\mathrm{w} / \mathrm{v})$ solid consistency. The suspensions were mechanically fibrillated using a super mass-colloider MKCA6-2J (Masuko Sangyo Co. Ltd., Kawaguchi, Japan) at $2500 \mathrm{rpm}$. The gap between the grinding stones was gradually adjusted to $-100 \mu \mathrm{m}$. It is well known that, due to the pressure exerted by the material being ground, a negative setting of gap does not necessarily imply clashing of the grinding surfaces. The motion zero position was defined at the contact position between the two grinding parts before loading fiber suspension. The samples were taken with the gap of $+50,+20,0,-20,-50,-80$, and $-100 \mu \mathrm{m}$ for $5,5,10,20$, 20, 10, and 10 passes, respectively. The preparation process is shown in Fig. 1c. The CNF produced from mechanical grinding were marked as CNF-G.

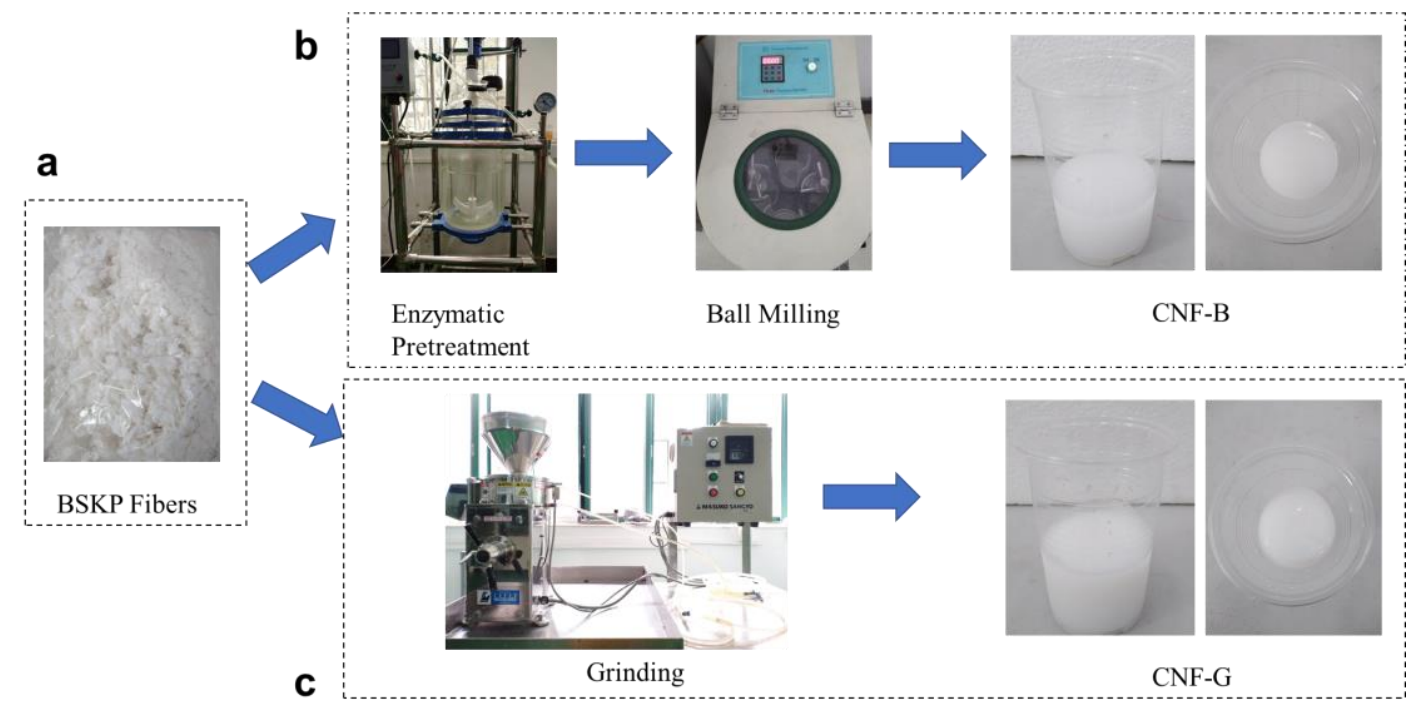

Fig. 1. Schematic flow diagram of CNF preparation. (a) BSKP fibers; (b) Representation of the enzymatic pretreatment and wet ball milling process used to obtain CNF-B; (c) Representation of the mechanical grinding process used to obtain CNF-G 


\section{Characterization}

Scanning electron microscopy (SEM) observations

The surface morphologies of fibers were analyzed by a field-emission scanning electron microscopy (FE-SEM Merlin, Zeiss, Oberkochen, Germany). The samples were dried at room temperature and coated with a thin layer of gold to ensure the conductivity before testing.

$X$-ray diffraction $(X R D)$ analysis

$\mathrm{X}$-ray diffraction measurement was performed using an X-ray diffractometer (D8 ADVANGE, Bruker, Karlsruhe, Germany) using a $\mathrm{Cu}$ Ka radiation at 100, which was operated at a voltage of $40 \mathrm{kV}$ and a current of $40 \mathrm{~mA}$ from $5^{\circ}$ to $60^{\circ}$ at a scanning rate of $4 \% \mathrm{~min}$. The sample was prepared for a thin sheet before testing. The crystallinity index (CrI) was calculated using Eq. 1 via the Segal method (Liu et al. 2018).

$$
C I(\%)=\frac{I_{200}-I_{a m}}{I_{200}} \times 100 \%
$$

where $I_{200}$ was the maximum intensity of the crystalline peak at $2 \theta$ between $22^{\circ}$ and $23^{\circ}$, and $I_{\mathrm{am}}$ was the minimum intensity of the amorphous cellulose at $2 \theta$ between $18^{\circ}$ and $19^{\circ}$.

\section{Degree of polymerization (DP)}

The average degree of polymerization was determined by viscosity $\left(25^{\circ} \mathrm{C}\right)$ of fiber solution in $0.5 \mathrm{~mol} / \mathrm{L}$ cupriethylenediamine hydroxide solution using an Ubbelohde viscometer. The DP value was determined from Eq. 2,

$$
D P^{0.905}=0.75[\eta]
$$

The intrinsic viscosity $[\eta]\left(\mathrm{cm}^{3} / \mathrm{g}\right)$ was calculated according to an ASTM method (Wang et al. 2018).

\section{RESULTS AND DISCUSSION}

\section{CNF Properties}

Dispersion of the CNF suspension can be indirectly reflected through the optical properties of the suspensions (Nie et al. 2018). Photographs of CNF suspensions (0.5\% $\mathrm{w} / \mathrm{v}$ ) from wet ball milling and mechanical grinding are shown in Fig. 2. The CNF suspensions were contained in glass tubes. A piece of green paper was used as background to visually demonstrate the opacity of the CNF suspension. The solution volume was limited to $8 \mathrm{~mL}$ and it was kept for $1.0 \mathrm{~h}$ standing. For each initial fiber sample, the CNF with various degrees of fibrillation had different levels of dispersion in water. As shown in Fig. 2a, the raw BSKP fibers did not present a homogeneous dispersion, being arranged as several groups of fibers enclosed by a cellulose matrix. The suspension prepared using enzymatic was almost completely precipitated. With the increment of ball milling time, the CNF-B suspensions showed better dispersion. As shown in Fig. 2b, the fibers (after 5 passes through the $50 \mu \mathrm{m}$ ) settled to the bottom of the tube. Fibrillation through grinding increased dispersity of the resultant fibrillated material, which can be seen from the increased opacities of the suspensions. After 20 passes through the $-20 \mu \mathrm{m}$ chamber, all samples were well dispersed in water, and became more and more transparent with increased numbers of passes of grinding. So the CNF-G was greater in thickness (a higher viscosity). 


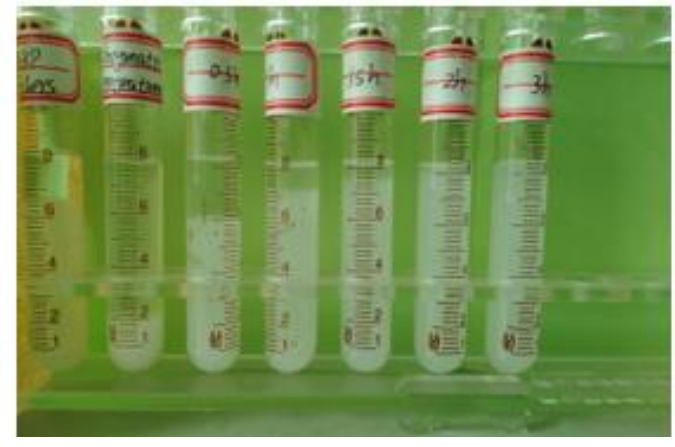

(a)

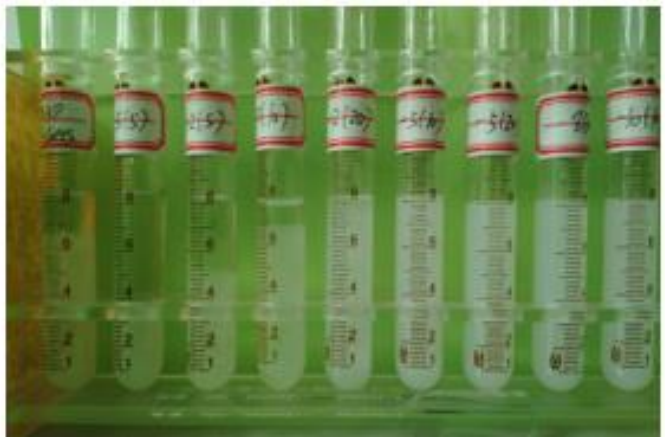

(b)

Fig. 2. Photographs of the suspensions of (a) CNF-B; and (b) CNF-G

\section{Morphological Characteristics of the CNF}

The morphology of fibers was investigated by using scanning electron microscopy (SEM). Figures 3(b1-b6) indicated that when the pulps were ball-milled for longer time periods, the proportion of intact fibers and the diameter of fibrils decreased as a result of fiber fragmentation. Ball milling for $1.5 \mathrm{~h}$ induced defibrillation with an average diameter of $33 \mathrm{~nm}$. The impact force, shear force, compression, and frictional force resulted in the reduction of size. After $3.0 \mathrm{~h}$ of ball milling, the diameter again was reduced to around 26 $\mathrm{nm}$. During ball milling, the fibers collided with the agate balls inside the container and imparted reduction (Ravindran et al. 2019).

The grinding pass number had a significant influence on the CNF properties. Figure 3(c1-c8) shows the SEM images of the nanofibril from grinding of pulps. The nanofibril diameter decreased with increasing number of grinding passes and progression of the fibrillation. The CNF produced by the grinding process were highly kinked, twisted, and entangled networks with fibril diameters ranging from tens of nanometers to microns (Wang et al. 2016). With the increment of grinding passes, the CNF showed more uniform nano-micro dimensions and a more highly networked structure. The raw BSKP fibers had diameters as wide as several microns. The SEM images revealed that the BSKP fibers (after grinding with a gap of $-50 \mu \mathrm{m}$ for 10 passes) were very much fibrillated and no microfibers could be detected. In the case of the initial BSKP fibers (before grinding with a gap of $-50 \mu \mathrm{m}$ for 10 passes), non-fibrillated fibers were observed. After grinding with a gap of $-50 \mu \mathrm{m}$ for 10 passes, stable and homogeneous colloidal suspensions were obtained, which had a gel-like appearance, and no phase separation was observed during storage.

\section{Average Degree of Polymerization}

Mechanical properties of the CNF are strongly dependent on fibril length. The DP is a measurement of the length and branching of cellulose chains; therefore, DP can be an intrinsic parameter of the mechanical properties of CNF (Wang et al. 2015). The enzyme that was used for enzymatic pretreatment in this work is an extensive commercial cellulase (Wang et al. 2018). After enzymatic pretreatment, the fibers were loosened, and the DP decreased rapidly by $40 \%$. Therefore, the application of enzymatic pretreatment to facilitate the fibrillation of cellulosic fibers is a cost-effective technology. As shown in Fig. $4 a$, the DP of CNF decreased rapidly at the initial stage of wet ball milling. For the ball milling time from $0 \mathrm{~h}$ to $0.5 \mathrm{~h}$, the DP of BSKP fibers decreased by $25 \%$. A moderate reduction in DP was observed with increasing the ball milling time. 

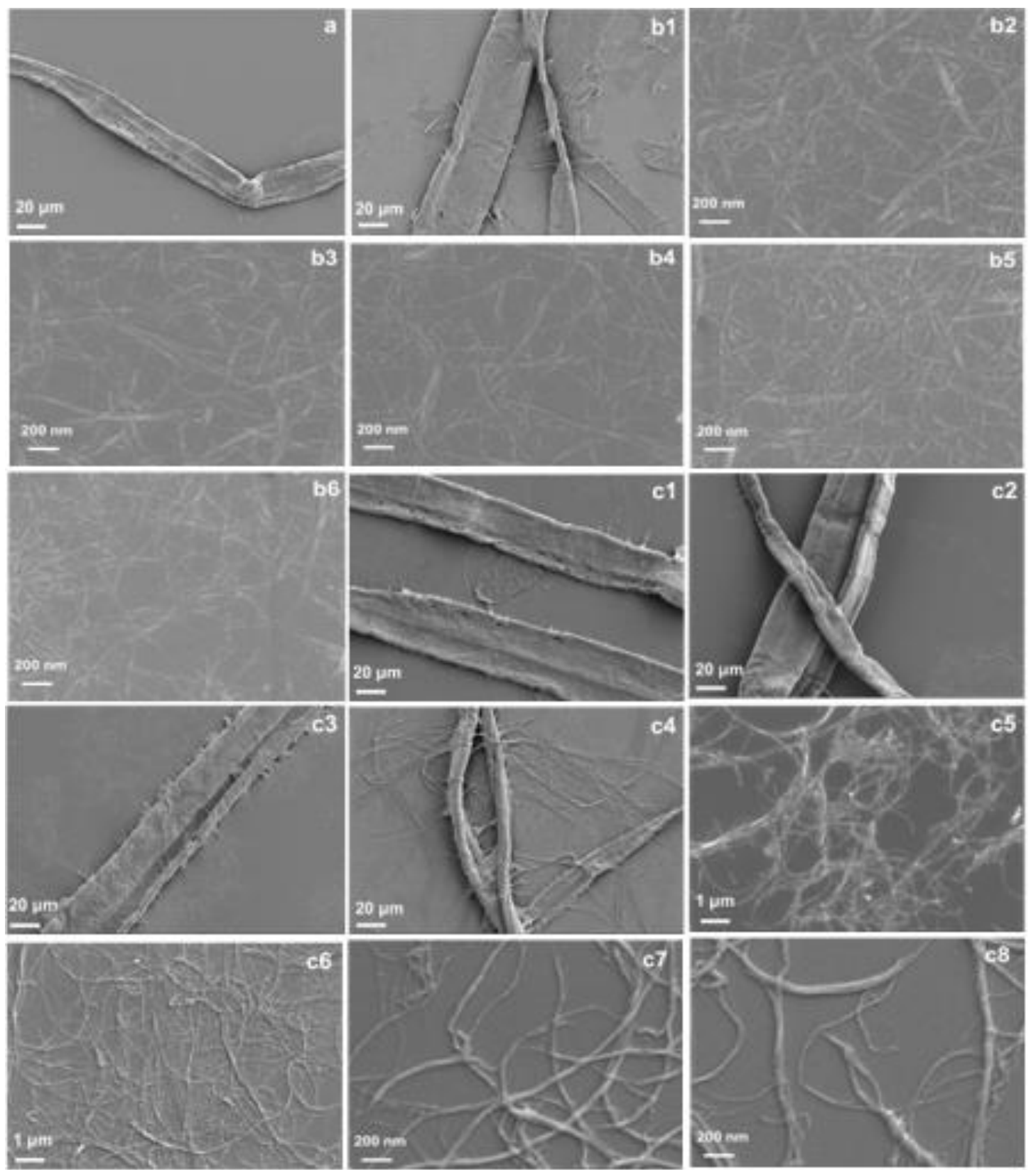

Fig. 3. The SEM images of fibrils produced from (a) BSKP fibers; (b1) BSKP fibers with enzyme pretreatment; (b2-b6) BSKP fibers with enzyme pretreatment followed by ball milling for $0.5 \mathrm{~h}, 1.0$ $\mathrm{h}, 1.5 \mathrm{~h}, 2.0 \mathrm{~h}$, and $3.0 \mathrm{~h}$; (c1) BSKP fibers after grinding with a gap of $+50 \mu \mathrm{m}$ for 5 passes; (c2) BSKP fibers after grinding with a gap of $+20 \mu \mathrm{m}$ for 5 passes; (c3) BSKP fibers after grinding with a gap of $0 \mu \mathrm{m}$ for 10 passes; (c4) BSKP fibers after grinding with a gap of $-20 \mu \mathrm{m}$ for 20 passes; (c5) BSKP fibers after grinding with a gap of $-50 \mu \mathrm{m}$ for 10 passes; (c6) BSKP fibers after grinding with a gap of $50 \mu \mathrm{m}$ for 20 passes; (c7) BSKP fibers after grinding with a gap of $-80 \mu \mathrm{m}$ for 10 passes; and (c8) BSKP fibers after grinding with a gap of $-100 \mu \mathrm{m}$ for 10 passes.

The high energy collision between the balls reduced the length of cellulose. The reduction of the DP induced by the grinding treatment was seen in Fig. 4b, which is consistent with previous reports (Velásquez-Cock et al. 2016). Ultrafine grinding of the pulp to isolate the nanofibers exposes the fibers to very high shear forces. The length of cellulose chain decreased as a result. 
(a)

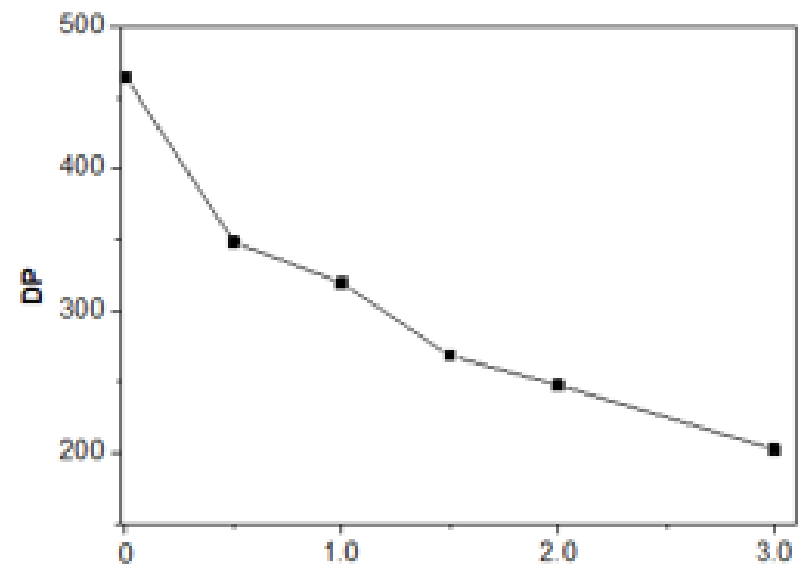

Ball milling time $(h)$ (b)

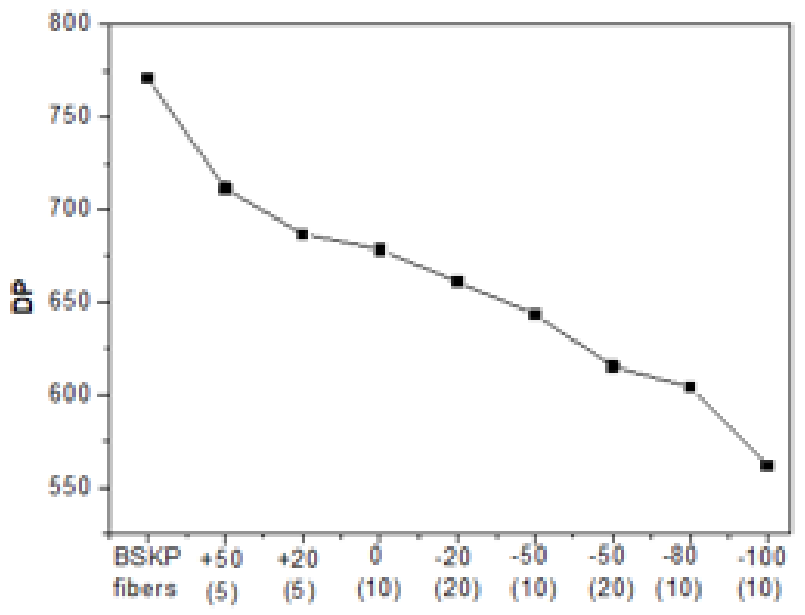

Grinding conditions

Fig. 4. (a) DP of BSKP fibers with enzyme pretreatment and BSKP fibers with enzyme pretreatment followed by different ball milling time; and (b) DP of BSKP fibers and BSKP fibers after different grinding conditions

\section{Crystal Structures of CNF}

The crystallinity of the CNF was analyzed by XRD. The XRD-profiles of BSKP fibers and fibrils prepared by ball milling and mechanical grinding are shown in Fig. 5. All the sheets showed cellulose-I structures with peaks at $2 \theta$ of $23^{\circ}$ and $18^{\circ}$, which belong to diffraction from the (200) and (110) planes, respectively (Hassan et al. 2018).

(a)

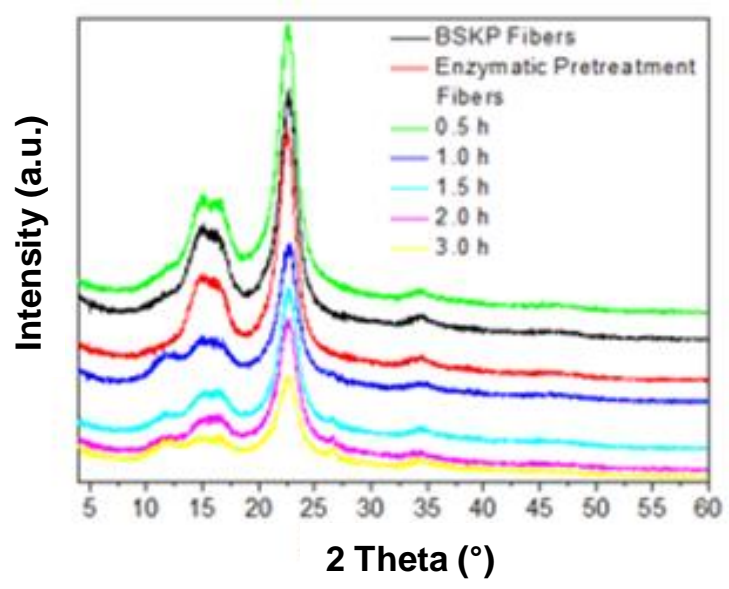

(b)

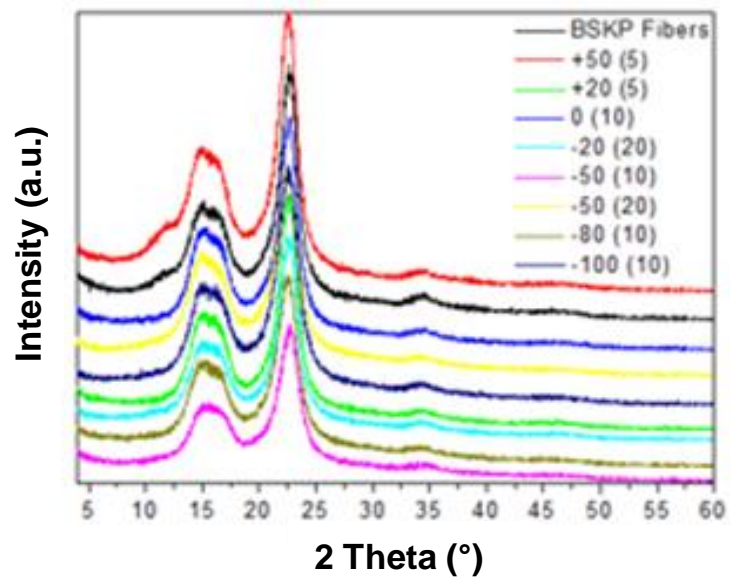

Fig. 5. X-ray diffraction patterns of (a) BSKP fibers; BSKP fibers with enzyme pretreatment and BSKP fibers with enzyme pretreatment followed by different ball milling time; (b) BSKP fibers and BSKP fibers after different grinding conditions

The enzymatic pretreatment and mechanical process had little effect on the crystalline structure of CNF. This indicated that the enzyme pretreatment and mechanical processes affected only the amorphous region and the surface of the crystalline region 
within cellulose domains.

The CrI was calculated according to the Segal method, and the results are shown in Tables 1 and 2 . It could be seen that the CrI increased with enzymatic pretreatment, changing from $76.3 \%$ to $78.6 \%$. The enzyme treatment mainly loosened the amorphous area of cellulose and did not cause hydroxylation of the amorphous area (Wang et al.2018). However, the sample treated only by ball milling showed completely contrary behavior, and the CrI decreased from $76.3 \%$ to $67.7 \%$. This should be attributed to the effect of ball milling, which provided high shear force from the collision between the different sizes of balls and the friction of balls with the wall of jar, leading to weakening the hydrogen bonding networks within the crystalline cellulose. As a result, the crystallinity of CNF was reduced after the ball milling treatment (Phanthong et al. 2017).

The crystallinity of CNF decreased with the increasing number of passes through mechanical grinding equipment, which is similar to the values found by Wang and Zhu (2016). Specifically, the CrI of BSKP fibers changed from $76.3 \%$ to $69.9 \%$. Before the grinding gaps down to -20 , the crystallinity index decreases slightly. This is because the fibers were dispersed when the gap between the grinding stones was wide. The fibers were not destroyed too much. Mechanical grinding appeared to indiscriminately disintegrate the cellulose into fragments by damaging the crystalline region, which resulted in reduced $\mathrm{CrI}$ (Chen et al. 2017).

Table 1. Crystallinity Indices of BSKP Fibers, BSKP Fibers with Enzyme Pretreatment, and BSKP Fibers with Enzyme Pretreatment Followed by Different Ball Milling Time

\begin{tabular}{|c|c|}
\hline Specimens & Crystallinity index (\%) \\
\hline Raw fibers & 76.3 \\
\hline Enzyme pretreated fibers & 78.6 \\
\hline $0.5 \mathrm{~h}$ & 77.2 \\
\hline $1.0 \mathrm{~h}$ & 76.2 \\
\hline $1.5 \mathrm{~h}$ & 74.7 \\
\hline $2.0 \mathrm{~h}$ & 72.5 \\
\hline $3.0 \mathrm{~h}$ & 67.7 \\
\hline
\end{tabular}

Table 2. Crystallinity Indices of BSKP Fibers and BSKP Fibers after Different Grinding Conditions

\begin{tabular}{|c|c|}
\hline Specimens & Crystallinity index (\%) \\
\hline Raw fibers & 76.3 \\
\hline$+50(5)$ & 75.8 \\
\hline$+20(5)$ & 75.7 \\
\hline $0(10)$ & 75.5 \\
\hline$-20(20)$ & 75.4 \\
\hline$-50(10)$ & 72.3 \\
\hline$-50(20)$ & 71.8 \\
\hline$-80(10)$ & 71.1 \\
\hline$-100(10)$ & 69.9 \\
\hline
\end{tabular}




\section{CONCLUSIONS}

The properties of cellulose nanofibril (CNF) produced from the cellulase-treated bleached softwood kraft pulp (BSKP) using various ball milling periods, grinding gaps, and numbers of grinding passes were evaluated. These conditions affected the morphology, mechanical, and physical properties of the CNF produced. The dispersity of the CNF increased with the increment of ball milling time and number of grinding passes. This tendency was proportional to the reductions in degree of polymerization and crystallinity. However, the CNF produced by grinding (CNF-G) was greater in thickness (a higher viscosity) and transparency than when the $\mathrm{CNF}$ was prepared by ball milling (CNF-B). The crystallinity indices of CNF-B were reduced more than that of CNF-G. This is attributed to the action of a different mechanism for the CNF-B preparation, where the CNF was disintegrated by the high energy collision between the balls. During the mechanical grinding, the multilayered structure and bonds were broken down by the shearing forces produced by the grinding stones, and the $\mathrm{CNF}-\mathrm{G}$ can be isolated from the pulp. As a result, the CNF-G appeared as polydisperse and entangled networks.

\section{ACKNOWLEDGEMENTS}

This research was financially supported by National Key R\&D Program of China (2017YFB0307902), Guangdong Provincial Science \& Technology Plan Projects (2015B020241001), National Natural Science Foundation of China (No. 31600471), China Postdoctoral Science Foundation (2019TQ0100), Fundamental Research Funds for the Central Universities (2019MS085 and 2017YFB0307902), and State Key Laboratory of Pulp and Paper Engineering (201833).

\section{REFERENCES CITED}

Abdul Khalil, H. P. S., Davoudpour, Y., Islam, N. Md., Mustapha, A., Sudesh, K., Dungani, R., and Jawaid, M. (2014). "Production and modification of nanofibrillated cellulose using various mechanical processes: A review," Carbohydrate Polymers 99, 649-665. DOI: 10.1016/j.carbpol.2013.08.069

Amiralian, N., Annamalai, P. K., Memmott, P., and Martin, D. J. (2015). "Isolation of cellulose nanofibrils from Triodia pungens via different mechanical methods," Cellulose 22 (4), 2483-2498. DOI: 10.1007/s10570-015-0688-x

Berglund, L., Noël, M., Aitomäki, Y., Öman, T., and Oksman. K. (2016). "Production potential of cellulose nanofibers from industrial residues: Efficiency and nanofiber characteristics," Industrial Crops and Products 92, 84-92. DOI: 10.1016/j.indcrop.2016.08.003

Bian, H. Y., Li, G. L., Jiao, L., Yu, Z. H., and Dai, H. Q. (2016). "Enzyme-assisted mechanical fibrillation of bleached spruce kraft pulp to produce well-dispersed and uniform-sized cellulose nanofibrils," BioResources 11(4), 10483-10496. DOI: 10.15376/biores.11.4.10483-10496

Chen, Y., Fan, D. B., Han, Y. M., Li, G. Y., and Wang, S. Q. (2017). "Length-controlled cellulose nanofibrils produced using enzyme pretreatment and grinding," Cellulose 24(12), 5431-5442. DOI: 10.1007/s10570-017-1499-z 
Du, L. X., Wang, J. W., Zhang, Y., Qi, C. S., Wolcott, M. P., and Yu, Z. M. (2017). “A co-production of sugars, lignosulfonates, cellulose, and cellulose nanocrystals from ball-milled woods," Bioresource Technology 238, 254-262. DOI: 10.1016/j.biortech.2017.03.097

Ewulonu, C. M., Liu, X., Wu, M., and Y. Huang. (2019). "Ultrasound-assisted mild sulphuric acid ball milling preparation of lignocellulose nanofibers (LCNFs) from sunflower stalks (SFS)," Cellulose 26, 4371-4389. DOI:10.1007/s10570-019-02382-4.

Francoa, T. S., Potulskia, D. C., Vianab, L. C., Forvillea, E., Andradea, A. S. d., and Muniz, G. I. B. d. (2019). "Nanocellulose obtained from residues of peach palm extraction (Bactris gasipaes)," Carbohydrate Polymers 218, 8-19. DOI:

10.1016/j.carbpol.2019.04.035

Hassan, M., Berglund, L., Hassan, E., Abou-Zeid, R., and Oksman, K. (2018). "Effect of xylanase pretreatment of rice straw unbleached soda and neutral sulfite pulps on isolation of nanofibers and their properties," Cellulose 25(5), 2939-2953. DOI: 10.1007/s10570-018-1779-2

Kim, H. J., Lee, S., Jungbae Kim, J., Mitchell, R. J., and Lee, J. H. (2013). "Environmentally friendly pretreatment of plant biomass by planetary and attrition milling," Bioresource Technology144, 50-56. DOI: 10.1016/j.biortech.2013.06.090

Kwon, J. H., Lee, S., Lee, J. W., Hong, Y. W., Chang, J. H., Sung, D., Kim, S. H., Sang, B. I., Mitchell, R. J., and Lee, J. H. (2015). "Improved sugar production by optimizing planetary mill pretreatment and enzyme hydrolysis process," BioMed Research International 2015. DOI: 10.1155/2015/267538

Kwon, J. H., Kang, H., Sang, B. I., Kim, Y., Min, J., Mitchell, R. J., and Lee, J. H. (2016). "Feasibility of a facile butanol bioproduction using planetary mill pretreatment," Bioresource Technology 199, 283-287. DOI:

10.1016/j.biortech.2015.08.074

Liu, X. Y., Jiang, Y., Qin, C. G., Yang, S., Song, X. P., Wang, S. F., and Li, K. C. (2018). "Enzyme-assisted mechanical grinding for cellulose nanofibers from bagasse: energy consumption and nanofiber characteristics," Cellulose 25(12), 7065-7078. DOI: 10.1007/s10570-018-2071-1

Long, L, F., Tian, D., Hu, J. G., Wang, F., and Saddler, J. (2017). “A xylanase-aided enzymatic pretreatment facilitates cellulose nanofibrillation," Bioresource Technology 243, 898-904. DOI: 10.1016/j.biortech.2017.07.037

Marinhoa, N. P., Cademartori P. H. G. d., Nisgoski, S., Tanobe, V. O. d. A., Klock, U., and Muñiz, G. I. B. d. (2020). "Feasibility of ramie fibers as raw material for the isolation of nanofibrillated cellulose," Carbohydrate Polymers 230, 115579. DOI: 10.1016/j.carbpol.2019.115579

Mondal, S. (2017). "Preparation, properties and applications of nanocellulosic materials," Carbohydrate Polymers 163, 301-316. DOI: 10.1016/j.carbpol.2016.12.050.

Nagarajana, K. J., Balajia, A. N., and Ramanujam, N. R. (2019). "Extraction of cellulose nanofibers from cocos nucifera var aurantiaca peduncle by ball milling combined with chemical treatment," Carbohydrate Polymers 212, 312-322. DOI: 10.1016/j.carbpol.2019.02.063

Nechyporchuk, O., Belgacem, M. N., and Bras, J. (2016). "Production of cellulose nanofibrils: A review of recent advances," Industrial Crops and Products 93, 2-25 DOI: 10.1016/j.indcrop.2016.02.016.

Nie, S. X., Zhang, K., Lin, X. J., Zhang, C.Y., Yan, D. Y., Liang, H. M., and Wang, S. F. (2018). "Enzymatic pretreatment for the improvement of dispersion and film 
properties of cellulose nanofibrils," Carbohydrate Polymers 181,1136-1142. DOI: 10.1016/j.carbpol.2017.11.020

Nobuta, K., Teramura, H., Ito, H., Hongo, C., Kawaguchi, H., Ogino, C., Kondo, A., and Nishino, T. (2016). "Characterization of cellulose nanofiber sheets from different refining processes," Cellulose 23(1), 403-414. DOI: 10.1007/s10570-015-0792-y

Osong, S. H., Norgren, S., and Engstrand, P. (2016). "Feasibility of ramie fibers as raw material for the isolation of nanofibrillated cellulose and nanofibrillated cellulose, and applications relating to papermaking: A review," Cellulose 23, 93-123. DOI: 10.1007/s10570-015-0798-5

Phanthong, P., Karnjanakom, S., Reubroycharoen, P., Hao, X. Y., Abudula, A., and Guan, G. Q. (2017). "A facile one-step way for extraction of nanocellulose with high yield by ball milling with ionic liquid," Cellulose 24(5), 2083-2093. DOI: 10.1007/s10570-017-1238-5

Qi, Y. P., Cheng, Z., Ye, Z., Zhu, H. L., and Aparicio, C. (2019). "Bioinspired mineralization with hydroxyapatite and hierarchical naturally aligned nanofibrillar cellulose," ACS Applied Materials Interface 31(11), 27598-27604. DOI: 10.1021/acsami.9b09443

Ravindran, L., Sreekala, M. S., and Thomas, S. (2019). "Novel processing parameters for the extraction of cellulose nanofibres(CNF) from environmentally benign pineapple leaf fibres (PALF): Structure-property relationships," International Journal of Biological Macromolecules 131, 858-870. DOI: 10.1016/j.ijbiomac.2019.03.134

Spence, K. L., Venditti, R. A., Rojas. O. J., Habibi, Y., and Pawlak, J. J. (2011). “A comparative study of energy consumption and physical properties of microfibrillated cellulose produced by different processing methods," Cellulose 18, 1097-1111. DOI: 1097-1111. 10.1007/s10570-011-9533-z

Velásquez-Cock, J., Gañán, P., Posada, P., Castro, C., Serpa, A., Gómez, C., Putaux, J.L., and Zuluaga, R. (2016). "Influence of combined mechanical treatments on the morphology and structure of cellulose nanofibrils: Thermal and mechanical properties of the resulting films," Industrial Crops and Products 85, 1-10. DOI: 10.1016/j.indcrop.2016.02.036

Wang, W. X., Mozuch, M. D., Sabo, R. C., Kersten, P., Zhu, J. Y., and Jin, Y. (2015). "Production of cellulose nanofibrils from bleached eucalyptus fibers by hyperthermostable endoglucanase treatment and subsequent microfluidization," Cellulose 22(1), 351-361. DOI: 10.1007/s10570-014-0465-2

Wang, S. D., Gao, W. H., Chen, K. F., Xiang, Z. Y., Zeng. J.S., Wang. B., and Xu, J. (2018). "Deconstruction of cellulosic fibers to fibrils based on enzymatic pretreatment," Bioresource Technology 267, 426-430. DOI: 10.1016/j.biortech.2018.07.067

Wang, Q. Q., and Zhu, J. Y.(2016). "Effects of mechanical fibrillation time by disk grinding on the properties of cellulose nanofibrils," Tappi Journal 15(6), 419-423.

Zhang, L. Y., Tsuzuki, T., and Wang, X. G. (2015). "Preparation of cellulose nanofiber from softwood pulp by ball milling," Cellulose 22(3), 1729-1741. DOI: 10.1007/s10570-015-0582-6

Zhang, K., Zhang, Y. H., Yan, D. P., Zhang, C. Y., and Nie, S. X. (2018). "Enzymeassisted mechanical production of cellulose nanofibrils: Thermal stability," Cellulose 25(9), 5049-5061. DOI: 10.1007/s10570-018-1928-7 
Zhang, L. Y., Jia, Y. M., He, H., Yin, J. L., Chen, R. Y., Zhang, C. Q., Shen, W., and Wang, X. G. (2018). "Multiple factor analysis on preparation of cellulose nanofiber by ball milling from softwood pulp," BioResources 13(2), 2397-2410. DOI: 10.15376/biores.13.2.2397-2410

Article submitted: February 9, 2020; Peer review completed: March 23, 2020; Revised version received and accepted: March 30, 2020; Published: April 6, 2020.

DOI: 10.15376/biores.15.2.3809-3820 